\title{
Apical microleakage assessment of teeth obturated with single-cone gutta-percha using two calcium silicate sealers and a resin sealer: an in vitro study
}

\author{
Kolla Vishal Babu1, ${ }^{\text {, }}$ Kalyan Satish R², Girija S Sajjan², Madhu Varma K², Ambika Sigadam1, \\ Gnana Sindhu Dutta ${ }^{1}$ \\ ${ }^{1}$ Postgraduate Student, 2 Professor, Department of Conservative Dentistry and Endodontics, Vishnu Dental \\ College, Bhimavaram, Andhra Pradesh, India.
}

\section{N F O R M A T I O}

\section{Article History \\ Received 2nd June 2021 \\ Received revised 22nd July 2021}

Accepted 9th August 2021

Available online $1^{\text {st }}$ December 2021

\section{K E Y W O R D S}

Apical microleakage

Dye penetration

Endoseal MTA

Endosequence BC

Single cone obturation
Background: The most desirable outcome of endodontic treatment is to achieve a fluid-tight seal of the root canal space. Root canal sealers are used in combination with core filling materials to fill the irregularities in the root canal, resulting in a three-dimensional seal that prevents bacterial regrowth.

Aim: This study was aimed to compare the apical sealing ability of three root canal sealers AH Plus, Endosequence BC, and Endoseal MTA, using a single cone gutta-percha obturation technique.

Materials and methods: Forty extracted human single-rooted mandibular premolar teeth were decoronated to a standardized length of $15 \mathrm{~mm}$ and instrumented using crown down technique with the ProTaper gold rotary file system to apical file size F3. The roots were randomly allocated into three experimental groups $(n=10)$ and two control groups $(n=5)$. All the samples in experimental groups were obturated with a matched taper single cone: Group 1, Group 2 and Group 3 were obturated using AH Plus, Endosequence BC and Endoseal MTA sealers, respectively. Samples were immersed in $1 \%$ Methylene blue dye solution for 72 hours, and then the roots were split longitudinally and observed under a stereomicroscope. Apical microleakage was measured from the apex to the most coronal level of dye penetration. The data obtained were subjected to statistical analysis.

Results: Samples in all the groups showed evidence of leakage, except in the negative control group. One-way ANOVA showed significant differences between the groups $(p=0.00132)$. Posthoc analysis exhibited a significant difference between group 2 and group 3 ( $p=0.0102$ ).

Conclusion: Endosequence BC showed a superior seal and less microleakage compared to the two other sealers used in this study using a single cone guttapercha obturation technique.

\section{Introduction}

The main intention of endodontic treatment is to eliminate microorganisms and to obtain a three-dimensional seal of the root canal space preventing it from

Correspondence: ${ }^{*}$ Corresponding author Email Address: vishalbds234@gmail.com@gmail.com

How to cite this article: Kolla VB, Kalyan Satish R, Sajjan GS, Madhu Varma K, Sigadam A, Dutta GS. Apical microleakage assessment of teeth obturated with single-cone gutta-percha using two calcium silicate sealers and a resin sealer: an in vitro study. Int J Dent Mater 2021;3(4): 100-105. 
reinfection [1]. Numerous bacteria are resistant to many irrigating solutions and intracanal dressings, such as calcium hydroxide, and persist in areas like lateral canals and dentinal tubules. As a result, extensive obturation is required to prevent apical or coronal leakage, as well as to entomb residual debris and recalcitrant bacteria [2,3]. An ideal root canal filling must seal all portals of exit to the periodontium, providing a fluid-tight seal of the root canal space [4].

An apical seal is the utmost essential factor for the success of endodontic therapy. About $58 \%$ of root canal treatment failures can be attributed to incomplete obturation of the root canal [5]. Hence, the apical sealing ability of root canal filling materials is considered the most vital when obturating a root canal. The commonly used filling material is gutta-percha (GP) in conjunction with sealer for obturation. Root canal sealer is essential in achieving complete seal by sealing the lateral canals, apical ramifications, with the possibility of attaining the good sealing ability to dentin, less solubility, good biocompatibility, mineralization to dentin, and formation of calcified tissues to seal the apex [6].

The single-cone obturation technique gained popularity after the increasingly widespread use of rotary nickel-titanium (NiTi) instruments and matched-taper GP cones. Moreover, this technique is considered simple, which causes less stress for both patient and practitioner [7]. New root canal sealers have recently been developed to replace traditional zinc oxide eugenol sealers. In particular, bioceramic-based sealers are gaining importance because of their alkaline $\mathrm{pH}$, chemical stability, Less shrinkage, and biocompatibility $[8,9]$. Bioceramic based root canal sealers such as Endosequence BC sealer and Endoseal MTA sealer are offered as a pre-mixed syringe and usually contain calcium silicate. AH Plus, on the other hand, is an epoxy bisphenol resin sealant that comes in two tubes: epoxide paste and amine paste $[10,11]$.

In endodontics, dye penetration, bacterial penetration, fluid filtering methods, and gas chromatography have been utilised to evaluate leakage. Dye penetration tests, however, appear to be most extensively utilised since they provide a quantitative result and do not require sophisticated materials and equipment [10].

This study was designed to compare the apical sealing ability of three different sealers using a single cone obturation technique with a dye penetration method

using the stereomicroscope.

\section{Materials and methods}

\subsection{Selection of samples and preparation}

The sample size was assessed based on the previous studies using the G Power 3.1 software with $80 \%$ power and 5\% significance. Forty extracted human mandibular premolars with a single root and canal were included in the study. The teeth with calcified canals, cracks or fractures, development defects, multiple canals, root caries, and endodontically treated teeth were excluded. For standardization, all the samples were decoronated to a length of $15 \mathrm{~mm}$ by using a double-faced diamond disc (KG Sorensen, Barueri, SP, Brazil). Pulpal tissue extirpation was done, and the working length was determined using a size $10 \mathrm{~K}$ file (Dentsply, Maillefer, Tulsa, OK, USA). Biomechanical preparation for all the samples was done in crowndown motion using ProTaper Gold (PTG, Dentsply Tulsa Dental Specialities, Tulsa, OK, USA) till F3 file size. Canals were irrigated between the use of files with $5 \mathrm{ml}$ of 3\% Sodium hypochlorite (Prime dental PVT LTD., India). To remove the smear layer, all canals were irrigated with $3 \mathrm{ml}$ of $17 \%$ ethylenediaminetetraacetic acid (DESmear, Anabond Stedman pharma research, India). The final rinse was performed by using $5 \mathrm{~mL}$ of distilled water to remove any remaining irrigating solution. All the irrigation procedure was followed using a side vented needle placed $1 \mathrm{~mm}$ short of the apical foramen. After irrigation, the canals were dried with sterile absorbent paper points (Prime Dental PVT LTD., India). To eliminate inter-operator variability, all intracanal procedures were performed by a single operator.

\subsection{Grouping and obturation of the Samples}

All the forty samples were randomly divided into five groups consisting of three experimental groups $(n=10)$ based on the sealer used for the obturation and one negative and one positive control group with five specimens $(n=5)$ in each. Samples in the negative control group did not receive obturation, while in the positive control group, the samples were obturated with single cone GP size F3 without sealer. In Group 1, AH Plus (Dentsply, Maillefer, Ballaigues, Switzerland) sealer was manipulated according to manufacturer's instructions and was coated to canal walls using a \#30 Lentulo spiral rotated at $300 \mathrm{rpm}$ and $3 \mathrm{~mm}$ away from 
the apex, and then all the samples were obturated using single cone obturation technique with sealer coated F3 size master cone GP. In Group 2, EndoSequence BC Sealer (Brasseler U.S.A., Savannah, GA) and in Group 3, Endoseal MTA sealer (Maruchi, Wonju, South Korea), the syringe tip was placed into the coronal one -third of the root canal, and sealer was deposited by compressing the plunger of the syringe. The master GP of F3 size was coated with sealer and slowly introduced into the canal, and all the samples were obturated using the single cone obturation technique. The excess GP in all the groups was seared at the orifice, and vertical compaction of the GP was performed. The canal orifices were sealed with Cavit-G (3M ESPE, Germany). The obturation quality was evaluated radiographically, and samples with inadequate obturation were excluded from the study and substituted with a new one. All samples were incubated for one week at $37^{\circ} \mathrm{C}$ and $100 \%$ humidity in an incubator to allow the complete setting of sealers.

\subsection{Preparation of samples for Stereomicroscopic evaluation of dye penetration}

The external root surfaces in the experimental and positive control groups were coated with two layers of nail varnish, excluding the apical $2 \mathrm{~mm}$ of the roots. However, the root surfaces of the negative control teeth were entirely coated with two layers of nail varnish. The samples were then immersed in a $1 \%$ Methylene blue dye solution for 72 hours. Following this, the samples were removed from the dye and rinsed under running tap water for 15 minutes, and dried. The nail varnish was removed with a BP blade no. 11 . The samples were sectioned longitudinally with a diamond disk by placing the groove in a buccolingual direction from coronal to apical, and the filling material was removed using an endodontic explorer to allow obvious assessment of linear dye penetration. For each sample, linear dye penetration was measured in millimetres from apex to the most coronal level of dye penetration using a stereomicroscope (Olympus BX50, Japan) at 30x magnification.

\subsection{Statistical analysis}

The obtained data were statistically analyzed using one-way ANOVA and Tukey's post hoc test with IBM SPSS version 22 (IBM Corporation, New Orchard Road Armonk, New York 10504-1722, United States). The level of statistical significance was set at $\mathrm{p}<0.05$.

\section{Results}

The negative control group showed no linear dye penetration, while the positive control group showed complete dye penetration through the root canal space (Figure 1). The mean and standard deviation of linear dye penetration of the groups are given in Table 1 . The maximum linear dye penetration was observed in group 2 and the minimum was in Group 2. The oneway ANOVA test revealed a significant difference between the groups $(\mathrm{p}=0.00132)$ (Table 1$)$.

In Tukey's posthoc analysis (Table 2), statistically significant differences were observed between group 2 and 3 ( $\mathrm{p}=0.0102)$. However, group 1 did not show significant differences with group $2(p=0.446)$ and group $3(\mathrm{p}=0.147)$.

\section{Discussion}

The success of endodontic therapy is accredited to various crucial factors such as meticulous instrumentation, thorough debridement, and three-dimensional obturation of root canal space with a fluid-tight seal [12]. Endodontic sealers have a key role in sealing the root canal system, entombing the residual bacteria, and filling the irregularities in the prepared canal system [13]. The adhesion between the root canal dentin and GP is important in preventing microleakage, which can be attained through the use of different sealers [14]. Therefore, sealers have a great effect on the sealing of the canal space and the success of treatment.

With the introduction of matched GP, the traditional obturation is replaced with simple single cone obturation [15]. This technique has been considered less effective in sealing the root canal because of the larger bulk of cement that can be anticipated in the absence of condensation, resulting in more voids and shrinkage [16]. Recently, there has been development in the formulation of root canal sealers with properties such as alkaline $\mathrm{pH}$, biocompatibility, and lack of shrinkage.

Various methods have been advocated in the literature for testing microleakage in teeth, but the dye penetration method is most widely used since it involves a simple technique and equipment and is economical [10]. Methylene Blue dye was used in this study as it has a high degree of staining, which allows easy quantitative assessment of the extent of dye penetration by linear measurement technique [6]. Furthermore, it diffuses easily and is not absorbed by the dentin ma- 


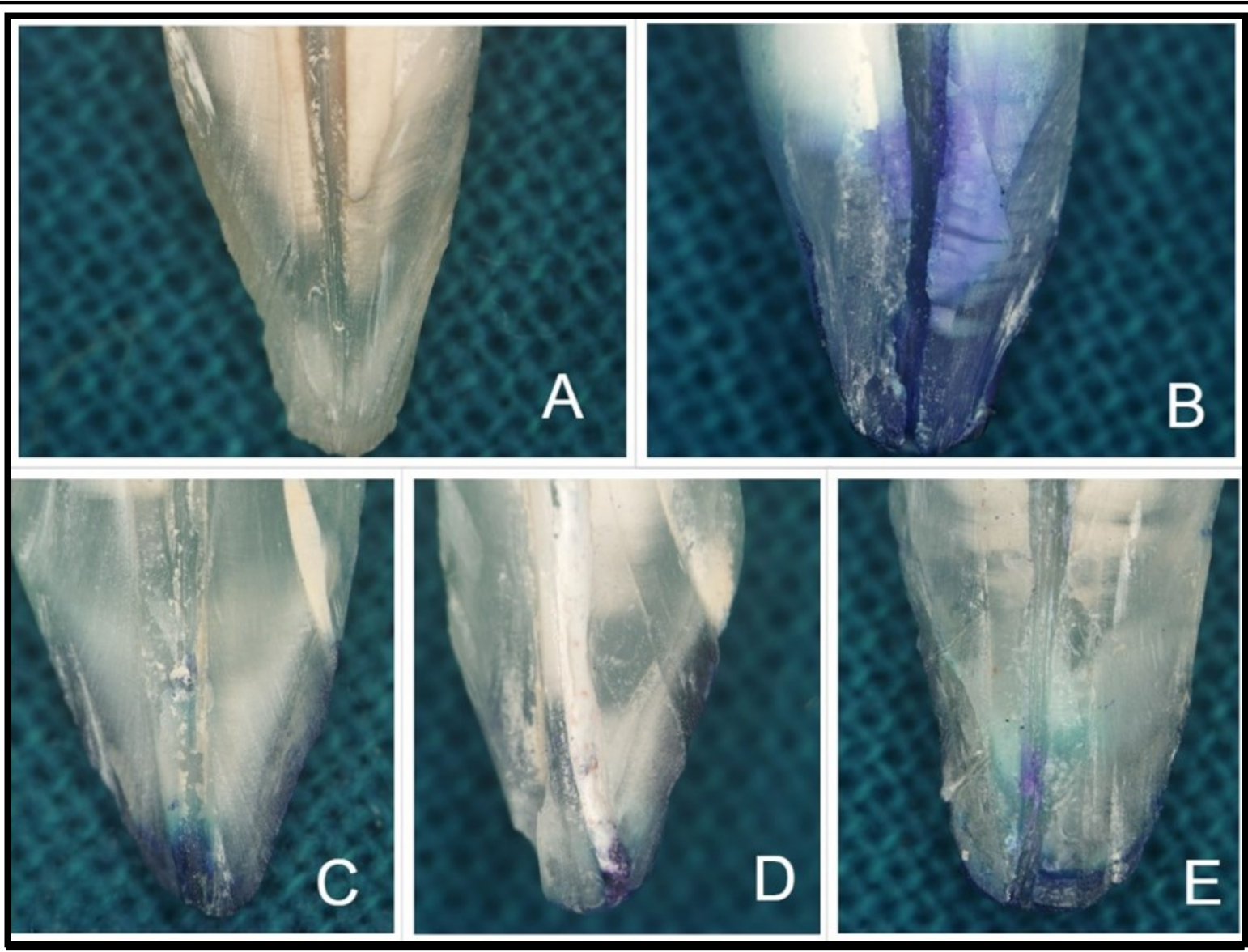

Figure 1: Stereomicroscopic images of tested samples showing linear dye penetration. Where A) negative control; B) Positive control, C) AH Plus, D) Endosequence BC, and E) Endoseal MTA

Table 2: Comparison of three experimental groups with respect to dye penetration by one-way ANOVA.

\begin{tabular}{lcccc}
\hline Groups & n & $\begin{array}{c}\text { Mean } \pm \text { Standard } \\
\text { deviation }\end{array}$ & F value & $\begin{array}{c}\text { Significance } \\
\text { (p value) }\end{array}$ \\
\cline { 1 - 3 } Group 1 - (AH Plus) & 10 & $1.8432 \pm 1.2068$ & & \multirow{2}{*}{5.104} \\
\cline { 1 - 3 } Group 2 - (Endosequence BC) & 10 & $1.1306 \pm 0.9342$ & 0.00132 \\
\cline { 1 - 3 } Group 3 - (Endoseal MTA) & 10 & $2.9670 \pm 1.6458$ & & \\
\hline
\end{tabular}

Table 2: Comparison of three experimental groups with respect to dye penetration by one-way ANOVA.

\begin{tabular}{llcc}
\hline & Groups & $\begin{array}{c}\text { Mean Difference } \pm \\
\text { Standard Error }\end{array}$ & $\begin{array}{c}\text { Significance } \\
(\boldsymbol{p} \text { value })\end{array}$ \\
\hline \multirow{2}{*}{ Group 1 - (AH Plus) } & Group 2 - (Endosequence BC) & $0.713 \pm 0.410$ & 0.446 \\
\cline { 2 - 4 } & Group 3 - (Endoseal MTA) & $1.124 \pm 0.410$ & 0.147 \\
\hline Group 2 - (Endosequence BC) & Group 3 - (Endoseal MTA) & $1.836 \pm 0.410$ & 0.0102 \\
\hline
\end{tabular}


trix apatite. Methylene blue was also the preferred choice because it has a molecular size and weight that is similar to a few bacterial by-products that have been reported to leak from the infected root canal into the periapical tissues causing irritation [17-19].

Results in the present study showed that Group 2, showed the minimum apical dye leakage with a mean value $(1.1306 \mathrm{~mm})$. The results of this study were in accordance with a previous study, which concluded that bioceramic sealer exhibited superior sealing compared with three different sealers by matched taper single cone obturation technique using dye penetration method [20]. Ballulaya et al. (2017) evaluated the microleakage of six different sealers and found that Endosequence $\mathrm{BC}$ had reduced microleakage, despite the fact that the obturation technique used was lateral condensation [21]. The minimum apical dye leakage value of Group 2 can be attributed to its ability to chemically bond to root canal dentin, and its extremely smaller particle size and hydrophilic nature allow it to flow into all aspects of the canal anatomy. In addition, the Endosequence BC root canal sealer exhibits a $0.2 \%$ expansion during the setting period, which supports the spread of the sealer over the dentin walls of the root canal and the filling of the lateral canals [22]. All these features may contribute to the lower apical dye leakage observed in the present study.

Group 1 showed more apical microleakage compared to Group 2 with a mean value $(1.8432 \pm 1.2068 \mathrm{~mm})$ but was not statistically significant $(p=0.446)$. This result is in agreement with a study, which concluded that the Endosequence BC sealer exhibited superior sealing compared with the AH Plus sealer using the dye penetration method. This poor sealing ability of the AH Plus sealer could be due to inadequate bonding between the AH Plus sealer and the gutta-percha point due to shrinkage because of the faster setting of the sealer, allowing fluid leakage at this interface [23].

Group 3 showed more apical microleakage with a mean value $(2.9670 \pm 1.6458 \mathrm{~mm})$ compared to Group 2 which was statistically significant $(p=0.0102)$ and with no significant statistical difference $(p=0.147)$ on comparison with Group 1. This finding is consistent with a study that found Endoseal MTA to have lower sealing ability than $\mathrm{AH}$ Plus when employed as a root canal sealer utilising the single cone obturation technique [24]. According to a study by Lim et al. (2015), the decreased sealing performance of Endoseal MTA can be attributed to its higher solubility $(0.7 \%)$ than
AH Plus (0.06\%) [25]. MTA based sealers do not bond to either dentin or gutta-percha which may be the reason for increased leakage observed in the present study [26,27].

\section{Conclusion}

Although none of the tested sealers prevents the apical microleakage completely, within the limitations of this study, it can be concluded that obturation with Endosequence $B C$ sealer using a single cone technique resulted in superior apical sealability compared to the other two tested sealers.

Conflicts of interest: Authors declared no conflicts of interest.

\section{Financial support: None}

\section{References}

1. Chandra SS, Shankar P, Indira R. Depth of penetration of four resin sealers into radicular dentinal tubules: a confocal microscopic study. J Endod. 2012;38(10):1412-6.

https://doi.org/10.1016/j.joen.2012.05.017

2. Grossman LI. Endodontic Practice, 10th ed. Philadelphia: Lea and Febiger; 1988:279.

3. Gutmann JL, Witherspoon DE. Obturation of the cleaned and shaped root canal system. In: Cohen S, Burns R, eds. Pathways of the Pulp, 8th ed. St Louis, MO: CV Mosby; 2004:293-364.

4. Farea M, Masudi SA, Wan Bakar WZ. Apical microleakage evaluation of system B compared with cold lateral technique: In vitro study. Aust Endod J. 2010;36(2):48-53.

https://doi.org/10.1111/j.1747-4477.2009.00187.x

5. Ingle JI and Taintor JF: Textbook of endodontics. 5th ed.

6. Vallari Jain, Prateeksha Chowdhry, Mamta Kaushik, Roshni Roshni, Neha Mehra. Qualitative and quantitative analysis of apical microleakage of different endodontic sealers. Int J Adv Res. 2019;7(6):476-481. https://doi.org/10.21474/IJAR01/9246

7. Sadr S, Golmoradizadeh A, Raoof M, Tabanfar MJ. Microleakage of single-cone gutta-percha obturation technique in combination with different types of sealers. Iran Endod J. 2015;10(3):199.

8. de Miranda Candeiro GT, Correia FC, Duarte MA, Ribeiro-Siqueira DC, Gavini G. Evaluation of radiopacity, $\mathrm{pH}$, release of calcium ions, and flow of a bioceramic root canal sealer. J Endod. 2012;38(6):8425. https://doi.org/10.1016/j.joen.2012.02.029 
9. Desai S, Chandler N. Calcium hydroxide-based root canal sealers: a review. J Endod. 2009;35(4):475-80. https://doi.org/10.1016/j.joen.2008.11.026

10. Salem AS, Saleh AR, Elmasmari HA. Assessment of Apical Leakage of Bioceramic Endodontic Sealer with Two Obturation Techniques. The Open Dentistry Journal. 2018;12(1): 1162-68. https:// doi.org/10.2174/1874210601812011162

11. Yang D.K., Kim S., Park J.W., Kim E., Shin S.J. Different Setting Conditions Affect Surface Characteristics and Microhardness of Calcium Silicate-Based Sealers. Scanning. 2018;2018:7136345. https:// doi.org/10.1155/2018/7136345

12. Hess D, Solomon E, Spears R, He J. Retreatability of a bioceramic root canal sealing material. J Endod. 2011;37(11):1547-9.

https://doi.org/10.1016/j.joen.2011.08.016

13. Hamid HA, Abdul-kareem J. The effect of smear layer on push-out bond strength to dentin of Bioceramic sealer (In vitro study). J Baghdad Coll Dent. 2013;25 (4):5-11. https://doi.org/10.12816/0015057

14. Remy V, Krishnan V, Job TV, Ravisankar MS, Raj CR, John S. Assessment of Marginal Adaptation and Sealing Ability of Root Canal Sealers: An in vitro Study. J Contemp Dent Pract. 2017;18(12):1130-4. https://doi.org/10.5005/jp-journals-10024-2188

15. Samiei M, Aghazade M, Farhadi F, Shahveghar N, Torab A, Pakdel SM. Sealing efficacy of single-cone obturation technique with MTA and CEM cement: an in vitro bacterial leakage study. Journal of Dental Research, Dental Clinics, Dental Prospects. 2014;8 (2):77.

16. Whitworth J. Methods of filling root canals: principles and practices. Endod Topics. 2005;12(1):2-4. https://doi.org/10.1111/j.1601-1546.2005.00198.x

17. Limkangwalmongkol S, Burtscher P, Abbott PV, Sandler AB, Bishop BM. A comparative study of the apical leakage of four root canal sealers and laterally condensed gutta-percha. J Endod. 1991;17(10):495-9. https://doi.org/10.1016/S0099-2399(06)81797-8

18. Punia SK, Nadig P, Punia V. An in vitro assessment of apical microleakage in root canals obturated with gutta-flow, resilon, thermafil and lateral condensation: A stereomicroscopic study. J Conserv Dent. 2011;14(2):173. https://doi.org/10.4103/0972-0707.82629

19. Bodrumlu E, Tunga U. Apical leakage of Resilon obturation material. J Contemp Dent Pract. 2006;7 (4):45-52. https://doi.org/10.5005/jcdp-7-4-45

20. Al-Kadhi AM, Al-Ani ZB, Al-Eanizi JA. Comparison of Apical Microleakage of Four Contemporary Endodontic Sealers by Dye Penetration Method. Int Medical J. 2019;26(3):237-40.

21. Ballullaya SV, Vinay V, Thumu J, Devalla S, Bollu IP, Balla S. Stereomicroscopic dye leakage measurement of six different root canal sealers. J Clin Diag- nostic Res. 2017;11(6):ZC65. https://doi.org/10.7860/ JCDR/2017/25780.10077

22. Zhang W, Li Z, Peng B. Assessment of a new root canal sealer's apical sealing ability. Oral Surgery, Oral Medicine, Oral Pathology, Oral Radiology, and Endodontology. 2009;107(6):e79-82. https:// doi.org/10.1016/j.tripleo.2009.02.024

23. Pawar SS, Pujar MA, Makandar SD. Evaluation of the apical sealing ability of bioceramic sealer, $\mathrm{AH}$ plus \& epiphany: An in vitro study. J Conserv Dent. 2014;17(6):579.

https://doi.org/10.4103/0972-0707.144609

24. Kim M, Park H, Lee J, Seo H. Microleakage Assessment of a Pozzolan Cement-based Mineral Trioxide Aggregate Root Canal Sealer. J Korean Acad Pediatr Dent. 2017;44(1):20-7. https://doi.org/10.5933/JKAPD.2017.44.1.20

25. Lim ES, Park YB, Kwon YS, Shon WJ, Lee KW, Min KS. Physical properties and biocompatibility of an injectable calcium-silicate-based root canal sealer: in vitro and in vivo study. BMC oral health. 2015;15 (1):1-7. https://doi.org/10.1186/s12903-015-0112-9

26. Weller RN, Tay KC, Garrett LV, Mai S, Primus CM, Gutmann JL, Pashley DH, Tay FR. Microscopic appearance and apical seal of root canals filled with gutta-percha and ProRoot Endo Sealer after immersion in a phosphate-containing fluid. Int Endod J. 2008;41(11):977-86.

https://doi.org/10.1111/j.1365-2591.2008.01462.x

27. Hatibović-Kofman Š, Raimundo L, Zheng L, Chong L, Friedman M, Andreasen JO. Fracture resistance and histological findings of immature teeth treated with mineral trioxide aggregate. Dent Traumatol. 2008;24(3):272-6. https://doi.org/10.1111/j.1600-9657.2007.00541.x 